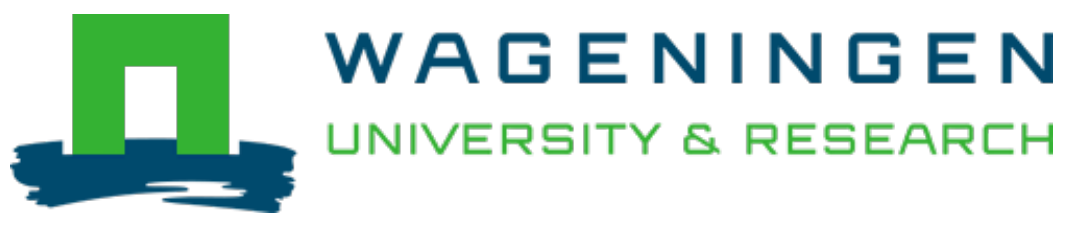

\title{
Encouraging sustainability in the workplace: a survey on the pro-environmental behaviour of university employees
}

\author{
Journal of Cleaner Production \\ Blok, V.; Wesselink, R.; Studynka, O.; Kemp, R.G.M. \\ https://doi.org/10.1016/j.jclepro.2014.07.063
}

This article is made publicly available in the institutional repository of Wageningen University and Research, under the terms of article $25 \mathrm{fa}$ of the Dutch Copyright Act, also known as the Amendment Taverne. This has been done with explicit consent by the author.

Article 25 fa states that the author of a short scientific work funded either wholly or partially by Dutch public funds is entitled to make that work publicly available for no consideration following a reasonable period of time after the work was first published, provided that clear reference is made to the source of the first publication of the work.

This publication is distributed under The Association of Universities in the Netherlands (VSNU) 'Article $25 \mathrm{fa}$ implementation' project. In this project research outputs of researchers employed by Dutch Universities that comply with the legal requirements of Article $25 \mathrm{fa}$ of the Dutch Copyright Act are distributed online and free of cost or other barriers in institutional repositories. Research outputs are distributed six months after their first online publication in the original published version and with proper attribution to the source of the original publication.

You are permitted to download and use the publication for personal purposes. All rights remain with the author(s) and / or copyright owner(s) of this work. Any use of the publication or parts of it other than authorised under article $25 \mathrm{fa}$ of the Dutch Copyright act is prohibited. Wageningen University \& Research and the author(s) of this publication shall not be held responsible or liable for any damages resulting from your (re)use of this publication.

For questions regarding the public availability of this article please contact openscience.library@,wur.nl 


\title{
Encouraging sustainability in the workplace: a survey on the pro-environmental behaviour of university employees
}

\author{
Vincent Blok ${ }^{\mathrm{a},{ }^{*}, \text { Renate Wesselink }}{ }^{\mathrm{b}}$, Oldrich Studynka ${ }^{\mathrm{a}}$, Ron Kemp ${ }^{\mathrm{c}}$ \\ ${ }^{a}$ Wageningen University, Management Studies Group, The Netherlands \\ ${ }^{\mathrm{b}}$ Wageningen University, Education and Competence Studies, The Netherlands \\ ${ }^{\mathrm{c}}$ Netherlands Authority for Consumers and Markets, The Hague, The Netherlands
}

\section{A R T I C L E I N F O}

\section{Article history:}

Received 20 November 2013

Received in revised form 23 July 2014

Accepted 23 July 2014

Available online $\mathrm{xxx}$

\section{Keywords:}

Human capital

Pro-environmental behaviour

Responsibility of individual employees

Sustainable development

Theory of planned behaviour

University

\begin{abstract}
A B S T R A C T
In order to enhance more sustainable behaviour in households, recent research focuses on the identification of factors that have an impact on sustainable or pro-environmental behaviour. The aim of this study is to identify factors that could predict pro-environmental behaviour in the workplace. While many studies focused on the behaviour of households, this study is one of the first that focuses exclusively on pro-environmental behaviour in the workplace. Based on a comprehensive literature review, two groups of factors were identified which could predict pro-environmental behaviour in the workplace: internal factors and external factors. Next, the model was tested among employees of a green university in the Netherlands. Based on the results of this study, it can be concluded that the theory of planned behaviour can explain pro-environmental behaviour in the workplace. At the same time, the results show that there are clear differences between factors influencing pro-environmental behaviour in households and in the workplace. Furthermore, also other factors like leadership support and exemplary pro-environmental behaviour by leaders are at stake in case of pro-environmental behaviour in the workplace, and have a significant positive impact on employee's intention to act pro-environmentally. The findings of this study have various managerial implications for green companies and organizations in general and green universities in particular.
\end{abstract}

๑) 2014 Elsevier Ltd. All rights reserved.

\section{Introduction}

In the last four decades, many researchers have investigated the negative impact of humankind on the carrying capacity of the earth (Friends of the earth, 2009; WWF, 2012). It is acknowledged that the increasing pollution of water, air and land resources on the one hand and the decrease of natural resources on the other hand is caused by human behaviour (Lehman and Geller, 2004). As a consequence, governments of many countries developed policies to restrict industrial pollution, preserve natural resources, reduce greenhouse gas emissions etc. of their citizens, and research additionally focused on the development of a more sustainable lifestyle in households (Kronenberg, 2007; Marchand and Walker, 2008), companies (Kürzinger, 2004; Rosner, 1995)

\footnotetext{
* Corresponding author. Wageningen University, Management Studies, P.O. Box 8130, 6700 EW, Wageningen, The Netherlands. Tel.: +31 317483623.

E-mail address: vincent.blok@wur.nl (V. Blok).
}

and educational institutions (Juárez-Nájera et al., 2010; Zsóka et al., 2013).

This raised the question of which factors have an impact on sustainable behaviour and how this behaviour could be enhanced. The research field of pro-environmental behaviour (PEB) emerged to investigate this. Based on a systematic literature review, Kollmus and Agyeman defined pro-environmental behaviour as a kind of behaviour that consciously seeks to minimise the negative impact of one's actions on the natural and built environment (Kollmuss and Agyeman, 2002). Various scientists and psychologists developed different terms describing the same or similar types of sustainable or pro-environmental behaviour, but all these studies focused on minimising the negative impact of human behaviour on the environment

Over the last 30 years, various environmental psychologists and sociologists have attempted to discover the factors that impact PEB in household settings. In order to find and describe these factors, different models have been developed. Several of them were developed many years ago, such as linear progression, altruism, empathy and pro-social behaviour (Kollmuss and Agyeman, 2002). 
Recently, some sociological models with regard to community social marketing (Mckenzie-Mohr, 2000) and deliberate inclusionary procedures (Jacqueline, 1999) were developed.

The problem with existing models is that they are applied to explain PEB in households, while PEB in the workplace is not or not sufficiently taken into account in current research. In this respect, there is a gap in the literature explaining PEB exclusively in the workplace. Since employees spend about one third of their time in an office, it is expected that PEB in the workplace will contribute significantly to the minimization of the negative impact of employee's actions on the natural and built environment. In order to enhance PEB in the workplace, this study focuses on specific factors that encourage PEB in the workplace. Based on a comprehensive literature review, factors that determine PEB in the workplace have been identified first. Secondly, a model is proposed in which these factors are linked to PEB. Finally, the model is tested on employees of Wageningen University and Research Centre, a green university in the Netherlands ( $N=411$ ) (hereafter Wageningen UR).

On the one hand, universities can be seen as regular employers of highly educated professionals. In this respect, Wageningen UR provides a case in which PEB can be studied exclusively in the workplace. On the other hand, however, universities have a special role in enhancing PEB, since they can contribute significantly to the education of PEB of students. Although recent research showed that the integration of education for sustainable development is still in an early phase in most higher education institutes (Lozano et al., 2013), universities could play a critical role in the transition toward a more sustainable society (Ki-Hoon et al., 2013; Lans et al., 2014; Sedlacek, 2013). This is not only achieved by adjustments of the curricula (Lambrechts et al., 2013; Pappas et al., 2013), but also by the performance of role model behaviour of teachers and other staff members (Lukman et al., 2013). In this respect, the study of PEB in the university setting is important because it does not only concern PEB in the workplace but also in an educational setting which may have an impact on the PEB of students. In the present study, however, the primary focus is on the university as a case in which PEB in the workplace can be studied.

\section{Theoretical framework}

In the past decades, researchers have tried to explain the reasoning why some individuals engage in PEB and others do not, for instance from a psychological (Duerden and Witt, 2010; Howell, 2013; Whitmarsh and O'Neill, 2010), behavioural (Csutora, 2012; Hargreaves, 2011) or educational perspective (Rodríguez-Barreiro et al., 2013). Due to different scientific backgrounds, most researchers tried to explain these factors from different perspectives. For instance, economists investigated the influence of external factors on actual behaviour such as having an income, the price of the product or other social-economic characteristics in relation to behaviour (Kip Viscusi et al., 2011; Swami et al., 2011), while management scientists focused on organizational capabilities (cf. Veldhuizen et al., 2013) and the importance of human capital (cf. Dentoni et al., 2012). Psychologists, on the contrary, tended to examine internal or psychological variables related to behaviour, such as values, beliefs and attitudes (De Groot and Steg, 2009; Kaiser et al., 1999; Nordlund and Garvill, 2002).

By means of a systematic literature review, Kollmuss and Agyeman (2002) examined PEB models in order to explain why people act or do not act pro-environmentally. They used the concept pro-environmental consciousness to describe the complex structure of these factors and their link to PEB. Derived from their review and other studies (Grob, 1991; Rioux, 2011; Schultz et al., 1995; Steg and Vlek, 2009), three groups of factors can be distinguished: 1) demographic factors, 2) external factors, and 3) internal human factors. Internal and external factors are seen from the viewpoint of the individual. In the literature, several examples can be found of specific demographic, internal or external factors which explain PEB. In this research, only internal and external factors are taken into account because these factors can probably be managed in order to enhance PEB in the workplace. Demographic factors will not lead to differentiated management policies and therefore are not taken into account in this research.

The point of departure in determining the internal and external factors in this research is Ajzen's established theory of planned behaviour (TPB) (Ajzen, 1991), because it has proven its value in former research studies (see for example Cordano et al., 2010; Rioux, 2011). Furthermore, it is one of the more commonly referenced theories in the field of environmental studies (Nye and Hargreaves, 2010). According to Ajzen and Fishbein (2004), the intention to act is the strongest predictor of actual behaviour. The antecedents of the intention to act are found in three constructs: one's attitude toward the behaviour, his or her subjective norms and his or her behavioural control over the situation in which he or she is expected to act and behave in a specific way. Attitudes concern a person's beliefs with regard to the consequences of specific acts (Cordano et al., 2010), while subjective norms consist of group-shared beliefs of how a person should act and behave (Conner and Armitage, 1998). Perceived behavioural control concerns a person's belief that he or she is 'in control' over the performance of the expected behaviour (Ajzen, 1991; Bandura, 1997).

The TPB was applied in the context of PEB by Rioux (2011). He found a positive correlation between battery collecting behaviour and the intention to act (cf. Cordano et al., 2010). Also other researchers applied the TPB to explain PEB, such as car use (Abrahamse et al., 2009; Bamberg and Schmidt, 2003; Wall et al., 2007), the use of public transportation (Heath and Gifford, 2002), recycling behaviour (Boldero, 1995; Mannetti et al., 2004), ecological behaviour (Kaiser et al., 1999; Kaiser and Gutscher, 2003) and pro-environmental behaviour (Oreg and Katz-Gerro, 2006). Although the TPB was mainly applied in households and most results mentioned above originate from household contexts, Nye and Hargreaves (2010) show that the TPB can also be applied in workplaces. In their study, they compare two interventions to improve PEB; one in households and one in the workplace. The most important difference they found in both contexts is that in workplaces it appears difficult to break out of old roles and, alternatively, that new ones can be difficult to play in the office. Furthermore, in workplaces there is a need for hard facts and data to justify new actions. In households the individual is more free to choose what and who to be in the context of his or her own household. Rather than hard data, it appears better to diffuse a kind of "folk knowledge" about what it means to live a green lifestyle (Nye and Hargreaves, 2010).

Based on the TPB, it is first of all expected that the intention to act predicts PEB in the workplace. Based on the TPB, it is secondly expected that attitudes, subjective norms and behavioural control have a positive relation with the intention to act proenvironmentally in the workplace. Besides, it is expected that several specific internal and external factors have a direct or indirect influence on PEB in the workplace.

\subsection{Internal factors}

In the PEB literature, several internal factors of PEB are identified as social factors (social norms, personal norms), cognitive factors (environmental awareness, intention to act, perceived behavioural control), and affective factors (values, attitudes toward the environment). 


\subsubsection{Social factors}

Social factors consist of social and personal norms. Norms can be defined as individual expectations about a person's behaviour in a particular social situation (Schwartz and Leonard, 1977). Personal norms represent one's own beliefs on how to act. Social norms represent the group-shared beliefs about how members of the group should act and behave. They are perceived to be enforceable through reward or punishment (Thøgersen 1999). If a social norm exists for a certain behaviour, people will normally employ this behaviour and perform it (Liebrand et al., 1992). Norms may help to understand why people diverge from acting in their own selfinterest, like in theories such as the theory of planned behaviour (Ajzen, 1991). According the TPB, the attitude toward behaviour, subjective norms, and perceived behavioural control all together shape an individual's behavioural intentions and behaviours.

With regard to PEB, Borgstede and Anders (2002) found that personal and social norms are related to the expectations people have with regard to PEB. Similarly, Nordlund and Garvill (2002) found that personal norms could be viewed as an important general predisposition to act pro-environmentally. Various studies have shown a positive correlation between PEB and personal and social norms (Bamberg and Schmidt, 2003; Bratt, 1999; Fornara et al., 2011; Harland et al., 2007, 1999; Matthies et al., 2012; Ramayah et al., 2012; Stern et al., 1999; Thøgersen 1999).

Based on the literature review on social factors, it is expected that personal and social norms also have a positive relation with PEB in the workplace. Based on the TPB, it is expected that social norms have a positive relation with the intention to act proenvironmentally.

\subsubsection{Cognitive factors}

The second group of internal factors concerns cognitive factors, which comprise environmental awareness and perceived behavioural control.

Environmental awareness can be seen as environmental knowledge and the recognition of environmental problems (Grob, 1995). Consequently, it is expected that the more people know about environmental problems, the more PEB they will show (Becker, 1978; Borden and Schettino, 1979; Hines et al., 1987; Katzev and Johnson, 1984). This relation is also confirmed by Van Birgelen et al. (2009), who concluded that eco-friendly purchase and disposal decisions for beverages were positively related to the environmental awareness of consumers and the eco-friendliness of their attitude.

In the context of households, Mannetti et al. (2004) found that the most important predictor of the intention to recycle is perceived behavioural control. Klöckner and Oppedal (2011) reported similar results. Similarly, Kaiser and Gutscher (2003) confirmed that perceived behaviour control is a significant direct predictor of ecological behaviour.

Based on the literature review on cognitive factors, it is expected that environmental awareness and perceived behavioural control are positively related to pro-environmental behaviour in the workplace. Based on the TPB, it is expected that perceived behavioural control has a positive relation with the intention to act proenvironmentally.

\subsubsection{Affective factors}

The last group of internal factors concern general values, environmental values and attitudes toward the environment. In recent years, various studies (De Groot and Steg, 2008; Schultz and Zelezny, 1998; Stern, 1999) used Schwartz's model of human values to classify and assess values (Schwartz, 1994; Schwartz and Mark, 1992). The model presents ten types of universal values, which were then integrated into four larger groups: 1) openness to change, 2) conservatism (traditionalism), 3) self-transcendence (altruism) and 4) self-enhancement (self-interest). In general, people who are interested in other people beyond their own social circle are more altruistic or self-transcendent. Research shows that self-transcendent people show more PEB than people without this category of values (Dietz et al., 1998; Karp, 1996; Stern et al., 1999; Stern and Dietz, 1994). Altruistic or self-transcendent values were found to have a positive effect on personal norms to behave proenvironmentally and also have a positive direct effect on PEB (De Groot and Steg, 2008; Stern et al., 1999; Wall et al., 2007). Karp (1996) found that self-transcendence and openness to change, among others, are strong predictors of PEB. On the contrary, values related to self-enhancement and conservatism are strong negative predictors of PEB. The third group of general values is therefore subdivided in general altruism or self-transcendence (measured by statements about social justice, equality and peace) and specific self-transcendence, e.g. environmental values (measured by statements about environmental protection, harmony with nature and respect for the earth). In a study by Rioux (2011), they showed that pro-environmental values predicted young people's behaviour with regard to the collection of used batteries. In another research by Clark et al. (2003), they showed that pro-environmental values might be necessary conditions to promote PEB.

Attitudes toward the environment also seem to have a positive effect on PEB. Meinhold and Malkus (2005) found that PEB attitudes significantly predicted PEB. Barr and Gilg (2006) showed that environmentalists clearly have a positive, confident and responsible attitude toward environmental protection.

Based on the literature review on affective factors, it is expected, first, that values related to openness to change and selftranscendence (altruism and environmentalism) are positively related to PEB in the workplace, while conservatism and selfenhancement (self-interest) are negatively related to PEB in the workplace. It is expected, secondly, that values related to openness to change and self-transcendence (altruism and environmentalism) have a positive effect on personal norms regarding PEB in the workplace, and therefore have an indirect positive effect on PEB, while conservatism and self-enhancement (self-interest) will have a negative indirect effect on PEB. With regard to attitudes toward the environment, a positive direct relation with PEB in the workplace is expected as well. Based on the TPB, it is expected that attitudes toward the environment have a positive relation with the intention to act pro-environmentally.

\subsection{External factors}

The second group of factors are external. PEB can be performed only if the required conditions and infrastructure are available, such as boxes for recycling in the workplace, a setting in which individual employees are allowed to regulate heating, have the possibility to buy sustainable products etc. The external factors related to the workplace are situational factors and leadership support.

Fliegenschnee and Schelakovsky (1998) concluded that situational factors play a key role in determining PEB. The less possibilities available to behave pro-environmentally, the less people are likely to show PEB. In recent research for instance, it became clear that access to kerbside recycling bins is an important situational factor with a positive impact on recycling behaviour (Derksen and Gartrell, 1993; Guagnano et al., 1995; Klöckner and Oppedal, 2011). Similarly, in a study on household waste management, Barr et al. (2001) defined situational factors related to PEB as "an individual's circumstances at a given time, represented by access to or knowledge and experience of waste management". It is assumed therefore, that PEB should not be too difficult; the easier it is to perform in a pro-environmental way, the more likely it is that 
people will actually perform PEB. This is confirmed by research by Borgstede and Anders (2002), who showed that people cooperate more frequently in situations in which fewer obstacles have to be overcome. The results of Fujii (2006) show that perceived ease of implementation will have a significant positive effect on intention to act pro-environmentally.

Nye and Hargreaves (2010) found that contrary to households, it is much more difficult to break out old roles and routines and establish new ones in the workplace. Furthermore, while it is relatively easy to change one's behaviour in the household, behavioural changes in the corporate context are primarily based on hard facts and data (Nye and Hargreaves, 2010). Management controls companies and organizations, thus leadership can be considered as an important external factor. The effectiveness of environmental management depends on leadership according to Ramus and Steger (2000) and Egri and Herman (2000). The impact of exemplary pro-environmental behaviour by leaders and heads of departments has to be distinguished from leadership support of employees to act pro-environmentally. Environmental leadership should be provided by a company's top management (Subhabrata Bobby et al., 2003) while the middle management is likely to have a critical impact on employees' attitudes and behaviour (Andersson et al., 2005; Daily et al., 2008; Ramus and Steger, 2000). Nye and Hargreaves (2010) also supported the well-recognized combination of social support, deliberation and feedback by managers. Yen and Yen (2012) concluded in their study that leadership is the primary driver of a firm's success in adopting green purchasing standards. Robertson and Barling (2012) found that leaders' environmental descriptive norms, leadership and PEB played an important role in the greening of organisations. Their study showed that the leaders influence their employees in the workplace by sharing values, inspirational motivation, intellectual stimulation, and establishing a relationship with their employees.

Based on the literature review on external factors, it is expected that situational factors are positively related to pro- environmental behaviour in the workplace. Furthermore, it is expected that exemplary PEB by leaders and leadership support is positively related to pro-environmental behaviour in the workplace.

Based on the literature review, the following factors that may have an impact on PEB in the workplace can be identified (see Fig. 1). Based on this conceptual model, the main research question of this article will be answered: which internal and external factors have an direct or indirect impact on PEB in the workplace?

\section{Research methods}

\subsection{Procedure and participants}

Data was collected from the employees of different departments of Wageningen UR $(N=411)$, ranging from PhD students to full professors (43.6\%), and ranging from secretaries to general managers (56.4\%). Wageningen UR is a Dutch university (about 7900 students and $1900 \mathrm{PhD}$ students) and one of the leading environmental education institutions in the Netherlands focussing on three interconnected core research areas: 1 . food and food production, 2 . living environment and 3. health, lifestyle and livelihood. The importance of sustainability for Wageningen University is expressed in its mission statement, "to explore the potential of nature to improve the quality of life," in its ambition to act as a role model in the field of sustainability in higher education and in its ambition to be a front runner in the area of sustainable operations management (Wageningen UR, 2012a; Wageningen UR, 2012b). In 2013, Wageningen UR received the SustainaBul Award 2013 for being the most sustainable university of the Netherlands.

The respondents were invited by email to participate in this study. After excluding 18 incomplete questionnaires, the sample consists of 411 respondents. The gender distribution of the sample was almost equal, $50.8 \%$ women and $49.2 \%$ men. The age

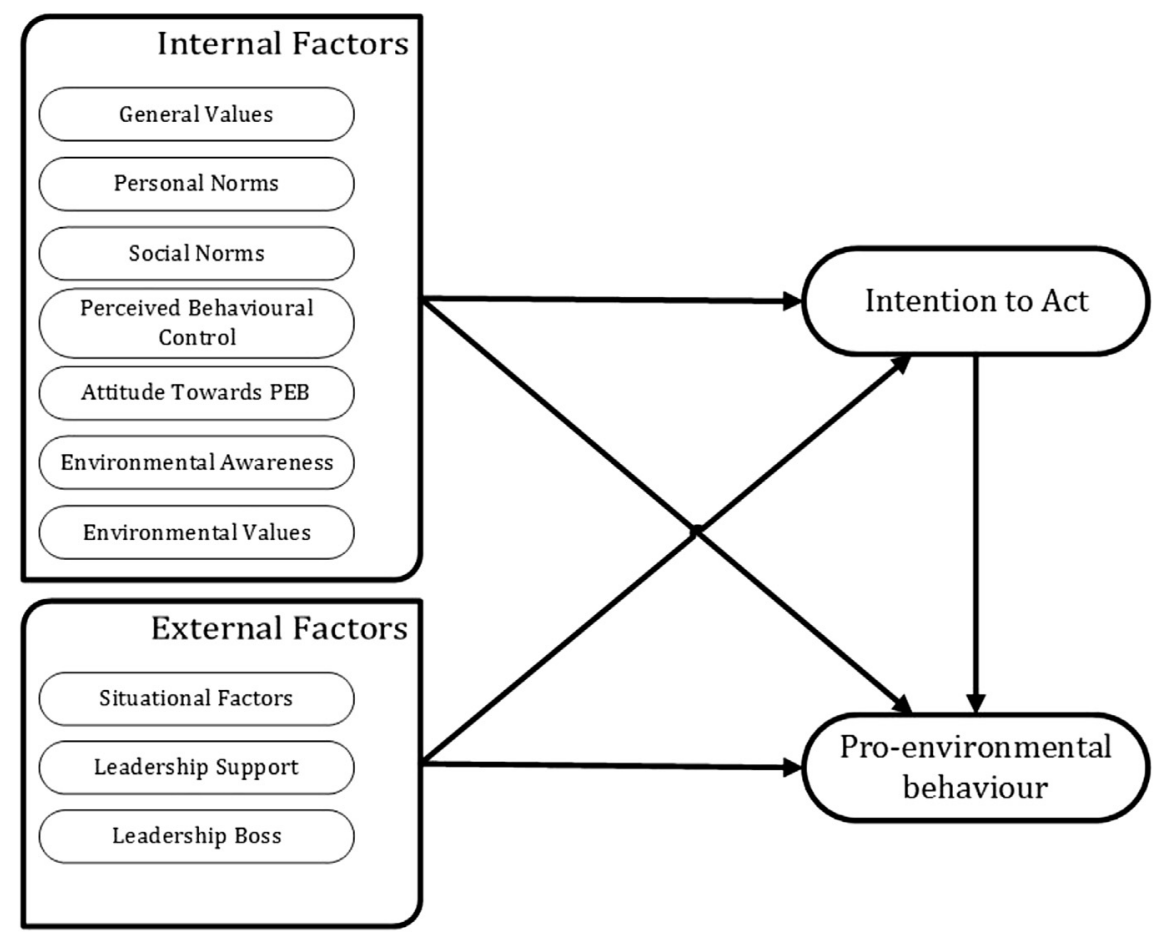

Fig. 1. Factors affecting pro-environmental behaviour (PEB) in the workplace. 
of the respondents ranged between 18 and 77 years old. The level of education was relatively high; $43.1 \%$ had a master degree and $29.0 \%$ had a doctoral degree. Because no detailed information of the population was available, personal characteristics of early (replied within a week, $n=349$ ) with late respondents (replied after a week, $n=62$ ) were compared. There were no significant differences for the gender, age, education level of the respondents or whether the respondent was scientific staff or non-scientific, indicating that nonresponse bias is not an issue.

\subsection{Questionnaire}

In the questionnaire, PEB and the internal and external factors were operationalized (see Appendix A for the questionnaire). The questions aimed to capture the actual behaviour that can be performed by the respondents in the offices and in relation to their work. Therefore, the questions measured how often they do certain activities related to heating, printing and copying, drinking hot beverages, sustainable shopping, computer use, light use and recycling. The answers were captured on a scale from 1 (='never') up to 5 (='always'). The lowest number indicated poor PEB and the highest the best possible. The number 0 indicated that there were no facilities or no possibilities available to perform PEB. To come to an overall score for PEB, the average is taken from the seven activities.

The constructs related to TPB where measured in the following way. The single item intention to act construct was measured by the cognitive representation of the respondent's readiness to perform PEB in the coming month. The intention was captured on the scale from 1 = 'strongly disagree' to $5=$ 'strongly agree'. A low score indicates a low intention and a high score suggests high intention to act pro-environmentally.

The three antecedents of the intention to act proenvironmentally are conceptualized in the following way. Subjective norms are conceptualized as social norms at work. The scale was based on Borgstede and Anders (2002) and measured the expectation of others to behave pro-environmentally in the workplace. The strength of the social norms was assessed by the respondent's (dis)agreement with statements related to the norms and measured on a scale from 1 (='absolutely not') up to 5 (='absolutely'). The higher numbers indicated a higher expectation of others to behave pro-environmentally at work. Attitudes were conceptualized in terms of attitudes with regard to PEB and measured by the degree to which behaving proenvironmentally was positively or negatively assessed. The scales ranged from 1 (='strongly disagree') to 5 (='strongly agree'). An average low score indicates low attitude and a high score a positive attitude toward PEB. Perceived behavioural control was conceptualized in terms of employee's perceptions of their ability to perform pro-environmentally and measured by two items, referring to people's perceptions of their ability to perform pro-environmentally. The respondents indicated their (dis)agreement on a scale from 1 (='strongly disagree') to 5 (='strongly agree'). A high score shows high perceived behaviour control.

With regard to the other internal and external factors which are expected to have a direct or indirect influence on PEB in the workplace, the following measures are used: The personal norms at work scale was based on Borgstede and Anders (2002) and measured the expectation of one's own behaviour to behave proenvironmentally on a five-point scale, ranging from 1 (='strongly disagree') to 5 (='strongly agree').

The environmental awareness scale consisted of eleven questions. The scale is based on Steg (1999) and also applied by
Gatersleben et al. (2002). The answers were captured on a fivepoint scale ranging from 1 (='low awareness') to 5 (='high awareness').

The general and environmental values were measured by the Value Inventory Scale (Schwartz, 1994; Schwartz and Mark, 1992; Nordlund and Garvill, 2002; Rioux, 2011; Stern et al., 1999.). The respondents' values were measured via sixteen items divided over five scales: Self-transcendence or environmentalism, selftranscendence or altruism, conservatism or traditionalism, selfenhancement or self-interest, and openness to change. The answers were captured by the original 7-point scale from -1 (='opposed to my values'), via 0 (='not important') up to 7 (='of supreme importance for me'). The average score of each group indicated the strength of the values.

The information need was measured by five items focussing on the different stakeholders that could provide information about environmental company policies and sustainability issues. The scales ranged from 1 (='strongly disagree') to 5 (='strongly agree'). An average low score indicates low information need and a high score a high information need.

The situational factors measured whether the employer provides good possibilities and provide facilities to show PEB. The answers were measured on a scale from 1 (='strongly disagree') to 5 (='strongly agree'). A high average score represents good conditions to show PEB at work.

The leadership factors represented the perceived exemplary PEB by leaders on the one hand (measured by three statements) and management practices by leaders to support PEB in the workplace on the other (measured by six statements). The scale was presented as 1 (='absolutely not') to 5 (= 'absolutely').

Lastly, the respondents were asked to indicate their gender (male or female) and exact age in years. For the analysis, six age-classes were made. The education level was indicated on the scale from the lowest compulsory education level to doctoral degree.

\subsection{Data analysis}

For data analysis, Stata v12.1 was used. Initially, a principal component analysis (PCA) with orthogonal rotation (varimax) method was used to test for unidimensionality for each separate variable with the criterion of eigen value $>1$. The factorability was examined by checking the anti-image correlation matrix (low values), and measures of sampling adequacy (MSAs) tested by Kaiser-Myer-Olkin (KMO > 0.50) and Bartlett's test of sphericity (significant at 5\%). All variables, except environmental awareness, proved to be unidimensional. ${ }^{1}$ Based on the content, environmental awareness was kept as one single construct.

The reliability of the scales was tested by Cronbach's alpha's to confirm good internal correlation of each item in the scale. A Cronbach's alpha above 0.7 indicates a good internal reliability. Second, in order to test the theoretical framework, ordinary least squares (OLS) regression was used.

\section{Results}

In Table 1, the descriptives of the constructs are presented. Pro-environmental behaviour has an average score of 2.99 with a standard deviation of 0.65 . $^{2}$ However, the different underlying activities score differently. The employees reported PEB heating

\footnotetext{
1 The results are available upon request.

2 As pro-environmental behaviour is measure by factual statements and not perceptual questions, it has the form of a formative scale. Cronbach's $\alpha$ is therefore not relevant for these scales.
} 
Table 1

Mean values, standard deviations, and scale reliability (Cronbach's $\alpha$ ) for the applied measures of factors affecting pro-environmental behaviour (PEB) in the workplace.

\begin{tabular}{llll}
\hline Variable & Mean & Std. Dev. & Cronbach's $\alpha$ \\
\hline Pro-environmental behaviour & $2.99^{\mathrm{b}}$ & 0.65 & \\
Heating & $2.39^{\mathrm{b}}$ & 1.14 & \\
Printing and copying & $3.87^{\mathrm{b}}$ & 0.87 & \\
Drinking & $3.33^{\mathrm{b}}$ & 1.31 & \\
Sustainable shopping & $2.11^{\mathrm{b}}$ & 1.29 & \\
Computer use & $3.80^{\mathrm{b}}$ & 1.05 & \\
Light use & $3.71^{\mathrm{b}}$ & 1.74 & \\
Recycling & $1.72^{\mathrm{b}}$ & 1.59 & \\
Attitude toward PEB & $3.82^{\mathrm{b}}$ & 0.35 & 0.86 \\
Information need & $3.37^{\mathrm{b}}$ & 0.81 & 0.89 \\
Self-transcendence-Altruism & $5.15^{\mathrm{a}}$ & 1.18 & 0.78 \\
Self-transcendence-environmentalism & $4.83^{\mathrm{a}}$ & 1.27 & 0.85 \\
Conservatism-traditionalism & $5.01^{\mathrm{a}}$ & 1.32 & 0.72 \\
Self-enhancement-self-interest & $2.23^{\mathrm{a}}$ & 1.27 & 0.80 \\
Openness to change & $4.52^{\mathrm{a}}$ & 1.24 & 0.75 \\
Environmental awareness & $3.94^{\mathrm{b}}$ & 0.53 & 0.85 \\
Personal norms & $4.10^{\mathrm{b}}$ & 0.67 & 0.84 \\
Social norms & $4.04^{\mathrm{b}}$ & 0.64 & 0.82 \\
Intention to act & $3.68^{\mathrm{b}}$ & 0.93 & - \\
Perceived behavioural control & $3.45^{\mathrm{b}}$ & 0.76 & 0.40 \\
Situational factors & $2.87^{\mathrm{b}}$ & 0.82 & 0.64 \\
Exemplary behaviour by leaders & $2.83^{\mathrm{b}}$ & 0.73 & 0.70 \\
$\quad$ leadership boss) & & & \\
Leadership support to act & $2.37^{\mathrm{b}}$ & 0.66 & 0.87 \\
pro-environmentally & & & \\
Gender & $0.49^{2}$ & 0.50 & - \\
Age & $3.76^{2}$ & 1.20 & \\
\hline a & & & \\
\hline
\end{tabular}

a Measured on a 9-point scale $-/-1$ to 7 .

b Measured on a 5-point scale 1 to 5 .

with an average of $2.39(\mathrm{SD}=1.14)$ on a scale from 1 to 5 . The second scale measured PEB represented by printing behaviour with an average score of 3.87 (SD $=0.87)$. The third scale, PEB drinking, reported an average score of 3.33 ( $S D=1.31$ ). PEB sustainable shopping showed an average score of 2.11 $(\mathrm{SD}=1.29)$. Computer use has an average score of 3.80 $(\mathrm{SD}=1.05)$, slightly higher than light use with an average score of 3.71 ( $\mathrm{SD}=1.74)$. Finally, recycling has the lowest average score of 1.72 (SD 1.59).

Attitude toward PEB was high and positive $3.82(\mathrm{SD}=0.35)$ with a Cronbach alpha of 0.86 . Information need has an average score of 3.37 ( $S D=0.81$ ) with a Cronbach alpha of 0.89 . Of the value constructs, self-transcendence-altruism showed the highest average score 5.15 ( $S D=1.18$ ) with relatively high standard deviations, followed by conservatism with an average of 5.01 $(\mathrm{SD}=1.32)$. The third highest was self-transcendence - environmentalism with the score 4.83 ( $\mathrm{SD}=1.27)$. Openness to change had an average score of 4.52 (SD = 1.24). Self-enhancement-selfinterest, showed a low mean score of 2.23 (SD =1.27). Compared to the other value constructs, this score should, however, be as low as possible as people interested only in their own are not willing to sacrifice for others. All Cronbach alphas of the value constructs are above 0.70 .

Environmental awareness had a mean score of $3.94(\mathrm{SD}=0.53)$. This score showed that the environmental awareness of the respondents is high. The social norm scale showed a high average of $4.04(\mathrm{SD}=0.64)$. The employees also reported high personal norms of a total average of $4.10(S D=0.67)$. The Cronbach alpha for these three scales are above 0.80 . The employees reported a relatively high intention to act 3.65 ( $S D=0.93$ ). Perceived behavioural control scored $3.45(\mathrm{SD}=0.76)$. The Cronbach alpha of 0.40 is below the threshold. It is decided, however, to keep this two-item construct in the analysis.

The situational factors reported a mean somewhat below the mid-point: 2.87 (SD = 0.82). The Cronbach alpha $(0.64)$ is somewhat below the threshold. The leadership factor exemplary behaviour averaged at $2.83(\mathrm{SD}=0.73)$. The leadership support of PEB averaged at 2.37 ( $S D=0.66)$. For these two constructs, the Cronbach alpha is above 0.70 .

To conclude, most variables show good reliability. Situational factors and especially perceived behavioural control are below the thresholds of 0.70 . In Appendix B, the correlations between the constructs are presented. The correlations are well below the threshold value of 0.80 indicating that discriminant validity is not a problem in this study.

To test the effects of the different factors on the proenvironmental behaviour in the workplace, OLS regression was used. The results of the regression analyses are reported in Table 2.

The overall model is significant with an F-statistic of 5.57. The $R^{2}$ is 0.19 . The variance inflation factor (VIF)-indices (between 1.16 and 4.80) are below the VIF-index threshold value of 10 (Field, 2009). This is an indication that multicollinearity is not an issue.

Of the factors, intention to act is the most significant one. The coefficient is 0.12 . This is in line with the literature which suggests that the intention to act is a direct and important driver for PEB (§2). Secondly, social norms are significant at the 5\% level. Higher perceived social norms toward pro-environmental behaviour have a positive effect on the actual proenvironmental behaviour of the individual. Also the leadership support to act pro-environmentally has a significant effect on pro-environmental behaviour; support of the organisation results in more pro-environmental behaviour of the employees. Finally, gender has a partial, i.e. at $10 \%$ level, effect on the proenvironmental behaviour; men show less pro-environmental behaviour compared to women. All other variables are not significant.

As intention to act has a strong significant effect on the actual pro-environmental behaviour, a second regression was performed in order to test whether the variables identified in the theoretical model have an effect on the intention to act and therefore, an indirect effect on the actual PEB. In Table 3, the regression results are presented.

Table 2

Direct effects of factors affecting pro-environmental behaviour (PEB) in the workplace on actual pro-environmental behaviour.

\begin{tabular}{|c|c|c|c|c|}
\hline & Coefficient & & Std. Err. & $p$-Value \\
\hline Attitude toward PEB & 0.029 & & 0.104 & 0.781 \\
\hline Information need & 0.042 & & 0.046 & 0.361 \\
\hline Self-transcendence-altruism & 0.029 & & 0.031 & 0.351 \\
\hline Self-transcendence-environmentalism & 0.019 & & 0.033 & 0.579 \\
\hline Conservatism-traditionalism & -0.028 & & 0.025 & 0.266 \\
\hline Self-enhancement-self-interest & 0.020 & & 0.026 & 0.427 \\
\hline Openness to change & -0.020 & & 0.026 & 0.445 \\
\hline Environmental awareness & 0.100 & & 0.076 & 0.185 \\
\hline Personal norms & -0.011 & & 0.096 & 0.911 \\
\hline Social norms & 0.200 & $* *$ & 0.101 & 0.047 \\
\hline Intention to act & 0.120 & $* * *$ & 0.044 & 0.007 \\
\hline Perceived behavioural control & -0.026 & & 0.044 & 0.556 \\
\hline Situational factors & 0.007 & & 0.040 & 0.868 \\
\hline $\begin{array}{l}\text { Exemplary behaviour by leaders } \\
\text { (leadership boss) }\end{array}$ & -0.016 & & 0.047 & 0.729 \\
\hline $\begin{array}{l}\text { Leadership support to } \\
\text { pro-environmental behaviour }\end{array}$ & 0.102 & $* *$ & 0.050 & 0.040 \\
\hline Gender & -0.114 & * & 0.063 & 0.072 \\
\hline Age & 0.010 & & 0.026 & 0.716 \\
\hline Constant & 0.979 & $* *$ & 0.433 & 0.024 \\
\hline $\begin{array}{l}\text { Model } F \text {-stat. } \\
R^{2}=0.19\end{array}$ & 5.57 & $* * *$ & & \\
\hline
\end{tabular}


Table 3

Direct effects of factors affecting pro-environmental behaviour (PEB) in the workplace on the intention to act pro-environmentally.

\begin{tabular}{lcccc}
\hline & Coefficient & & Std. Err. & $p$-Value \\
\hline Attitude toward PEB & 0.286 & $* *$ & 0.118 & 0.015 \\
Information need & 0.097 & $*$ & 0.052 & 0.062 \\
Self-transcendence-altruism & -0.001 & & 0.036 & 0.970 \\
Self-transcendence-environmentalism & 0.046 & & 0.038 & 0.228 \\
Conservatism-traditionalism & 0.014 & & 0.029 & 0.624 \\
Self-enhancement-self-interest & -0.022 & & 0.029 & 0.459 \\
Openness to change & 0.013 & & 0.030 & 0.659 \\
Environmental awareness & 0.268 & $* * *$ & 0.085 & 0.002 \\
Personal norms & 0.226 & $* *$ & 0.109 & 0.039 \\
Social norms & 0.229 & $* *$ & 0.114 & 0.046 \\
Perceived behavioural control & 0.237 & $* * *$ & 0.049 & 0.000 \\
Situational factors & -0.075 & & 0.046 & 0.102 \\
Exemplary behaviour by leaders & 0.109 & $* *$ & 0.053 & 0.041 \\
$\quad$ leadership boss) & & & & \\
Leadership support to PEB & 0.061 & & 0.057 & 0.283 \\
Gender & -0.167 & $* *$ & 0.071 & 0.020 \\
Age & 0.013 & & 0.030 & 0.668 \\
Constant & -1.971 & $* * *$ & 0.484 & 0.000 \\
Model $F$-stat. & 23.15 & $* * *$ & & \\
$R^{2}=0.48$ & & & & \\
\hline$N=411 ;{ }^{*} p<0.10,{ }^{* *} p<0.05,{ }^{* * *} p<0.01$. & & & & \\
\hline & & & &
\end{tabular}

The overall model is significant with an F-statistic of 23.15. The $R^{2}$ is 0.48 . Also in this regression, multicollinearity is not an issue as the variance inflation factor (VIF)-indices (between 1.14 and 4.75) are below the threshold value of 10 .

Perceived behavioural control is the most significant factor explaining the intention to act with a coefficient of 0.237 . Further, the attitude toward PEB has a strong positive effect on the intention to act. This is supported by the need for information. People who want to be informed are also more inclined to act. None of the value constructs have a significant effect on the intention to act. The environmental awareness also has a strong and significant effect on the intention to act. The coefficient is 0.268. Both the personal (0.226) and social norms (0.229) have a positive effect on the intention to act pro-environmentally. ${ }^{3}$ The coefficients for both norms are more or less the same. Exemplary behaviour by leaders is important for the intention to act whereas leadership support to act pro-environmentally is not significant to the intention to act pro-environmentally. Finally, also here, gender has a significant effect; men have a lower intention to act compared to women.

\section{Discussion}

The findings clearly show that the TPB can explain PEB in the workplace. The intention to act is the most significant factor to determine PEB in the workplace and all three antecedents of the intention to act are significant as well. This is in line with the literature which suggest that the intention to act is a direct and important driver for actual behaviour in general and PEB in particular (cf. Cordano et al., 2010; Rioux, 2011; §2).

While previous studies already demonstrated the applicability of TPB in the context of PEB in households (i.a. Abrahamse et al., 2009; Heath and Gifford, 2002; Kaiser et al., 1999; Mannetti et al., 2004; Oreg and Katz-Gerro, 2006), the results of this study show that TPB is insufficient to explain PEB in the workplace completely, since other factors are important as well. In the context of the workplace, especially social norms and leadership

\footnotetext{
${ }^{3}$ Of the identified values, only self-transcendence-environmentalism has a significant positive effect on personal norms (0.149) and therefore an indirect effect on the intention to act pro-environmentally.
}

support to act pro-environmentally have an impact on PEB. This is comprehensible, since employees collaborate intensively with other team-, business unit- or department members in their work. In these collaborations, social norms are important and will have an impact on PEB as well. These results are also comparable with the results of Nye and Hargreaves (2010). According to their work it is important to make the implicit rules of conventional office routines more explicit, while renegotiating their meaning in incremental fashion and encouraging people to conform to it. With regard to leadership support, it is already acknowledged in the literature that supervisory support by managers (Ramus and Steger, 2000) and commitment of managers (Epstein, 2008) encourages initiatives of employees with regard to (corporate) sustainable behaviour.

At the same time, several factors of PEB in households are not confirmed in this research. Personal norms, environmental awareness and self-transcendent values (altruism and environmental values) do not have a significant positive relation with PEB in the workplace. Environmental values only have a positive significant impact on three out of the seven types of proenvironmental activities (buying, drinking and printing) while conservative values have a negative significant impact on one out of the seven types of pro-environmental activities (buying).

The difference between the impact of these factors on PEB in households and in the workplace may be explained by the fact that employees cannot act completely according to their own personal norms and values in the workplace. They are primarily dependent on the norms, values, roles and routines of the company (cf. Nye and Hargreaves, 2010) and these are difficult to change. In the business ethics literature for instance, it is acknowledged that the ethical decision-making process of employees and managers is less dependent on their personal values and more dependent on the everyday demands and commercial pressures of the companies they work for (Bartlett, 2003; cf. Liedtka, 1991). Jackall even concludes that unethical behaviour of employees and managers is not due to individual moral deficiencies such as personal values, but due to the bureaucratic structures (Jackall, 1988) and the culture of modern organizations (Cassell et al., 1997; cf. Blok, 2013). This distinction between personal and corporate norms and values may explain why the direct impact of personal norms, environmental awareness and self-transcendent values (altruism and environmental values) on PEB in households, as it is suggested in the literature (i.a. Clark et al., 2003; Dietz et al., 1998; De Groot and Steg, 2008; $\S 2.1 .3)$, is not confirmed in this study of PEB in the workplace.

Because a direct impact of these internal factors on PEB in the workplace had to be rejected, the indirect impact of these factors on the intention to act pro-environmentally was tested subsequently. The results show clearly that environmental awareness and personal norms have a significant impact on the intention to act pro-environmentally and therefore, have an indirect positive impact on PEB in the workplace. With regard to the impact of selftranscendent values (altruism and environmental values) on the intention to act pro-environmentally, no significant relation was found. It can be concluded that, while environmental awareness and personal norms may have a direct impact on PEB in households according to the literature, only an indirect impact of these factors is found in case of PEB in the workplace. Furthermore, it can be concluded that, while self-transcendent values (altruism and environmental values) may have a direct impact on PEB in households according to the literature, no direct impact of values is found in case of PEB in the workplace. Environmental values only have a significant positive effect on personal norms and therefore an indirect effect on the intention to act pro-environmentally in the workplace. In households individuals are more free to choose and 
that makes that their values come into play more easily than in office-settings were employees ought to comply with rules and routines.

At the same time, the findings of this research show clearly that exemplary behaviour by leaders has a significant impact on the intention of employees to act pro-environmentally. This result confirms other research in which role models are stressed (i.a. Egri and Herman, 2000; Ramus and Steger, 2000; Subhabrata Bobby et al., 2003; §2.2). Wirternberg et al. (2008) for instance argues that new behaviour is more likely to appear if employees see it modelled by their managers and 'significant others' with whom they wish to identify (Cassell et al., 1997). It is striking that the situational factors do not have a significant direct or indirect relation to PEB in the workplace.

\section{Conclusions}

This study focused on specific factors that have an impact on PEB in the workplace. Based on a comprehensive literature review, a conceptual model was developed in which internal and external factors were linked to PEB in the workplace. Next, the model was tested among employees of Wageningen UR. Based on the results of this study, the main research question can be answered: which internal and external factors have a direct or indirect impact on PEB in the workplace?

It can be concluded, first, that TPB can explain PEB in the workplace. The intention to act is the most significant factor to determine PEB in the workplace and all three antecedents of the intention to act are significant in this study. Secondly, it can be concluded that TPB is insufficient to explain PEB in the workplace completely, since other factors are important as well. Based on the results of this study, it can be concluded that especially social norms and leadership support to act pro-environmentally have an impact on PEB in the workplace. Although this study makes clear that environmental awareness and personal norms do not have a direct impact on PEB, it can be concluded that environmental awareness and personal norms have a significant impact on the intention to act pro-environmentally and therefore, have an indirect positive impact on PEB in the workplace. In this respect, it can be concluded that there are clear differences between factors influencing PEB in households and PEB in the workplace. Finally, it can be concluded that exemplary behaviour by leaders has a significant effect on the intention of employees to act pro-environmentally.

The findings of this research have various managerial implications for green companies and organizations in general and for green universities in particular. Since the TPB is applicable in case of PEB in the workplace, managers should focus on interventions which increase the behavioural control of employees, the social norms and employee's attitudes with regard to PEB. Furthermore, they should focus on managerial support of employees to act pro-environmentally, as this will have a strong positive effect on PEB in the workplace. Finally, the manager's role as role model with regard to PEB should be acknowledged, developed and enhanced, as exemplary behaviour by managers will increase employee's intention to act pro-environmentally significantly.

Although the measurements used in this study are reliable, given the high cronbach alphas, only one specific organization was involved in this research. In order to increase the generalizability of the findings, this research should first of all be repeated in other contexts than green universities, like big corporations or governmental organizations. Secondly, future research should focus on the relation between PEB in universities and education of PEB of students. It may be expected for instance that exemplary behaviour of scientific and supporting staff members will have a direct or indirect positive effect on PEB of students. Thirdly, more research is needed with regard to the different types of proenvironmental behaviour in the workplace (heating, printing and copying, drinking, sustainable shopping, computer use, light use, waste management, commuting etc.) and the impact of the various internal and external factors on these particular types of behaviour. It seems to be the case that the factors influence different kinds of behaviour, since this research for instance showed the positive impact of environmental values on buying, drinking and printing behaviour (and not on the use of light, computers and heating for instance). Fourthly, additional research on the identified internal and external factors is needed. In the current research, the independent variables were measured by either a single question or based on a scale which consists of various items. This method does not necessarily capture the whole measured construct. Fifthly, additional research on the relation between the intention of employees to act proenvironmentally and their actual PEB in the workplace is needed. In the current research, the results are based on selfreported questionnaires without the possibility to control the respondents' answers. Finally, future research should focus on additional factors that may have an influence on PEB in the workplace, e.g. the locus of control or the perceived health threats.

\section{Appendix A}

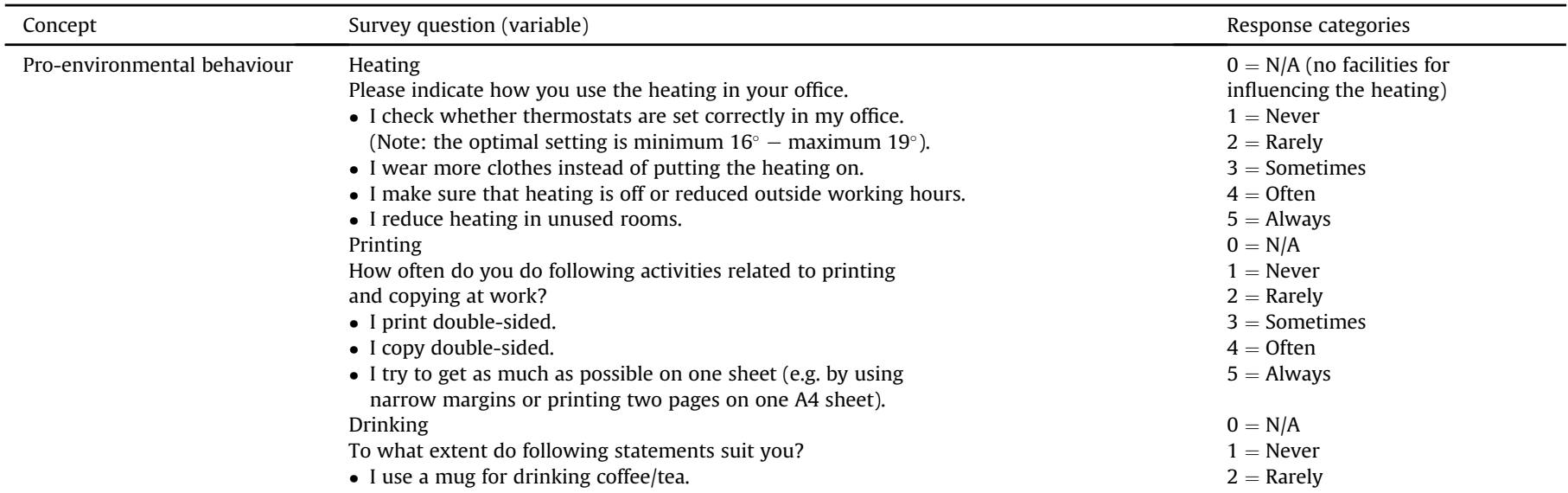




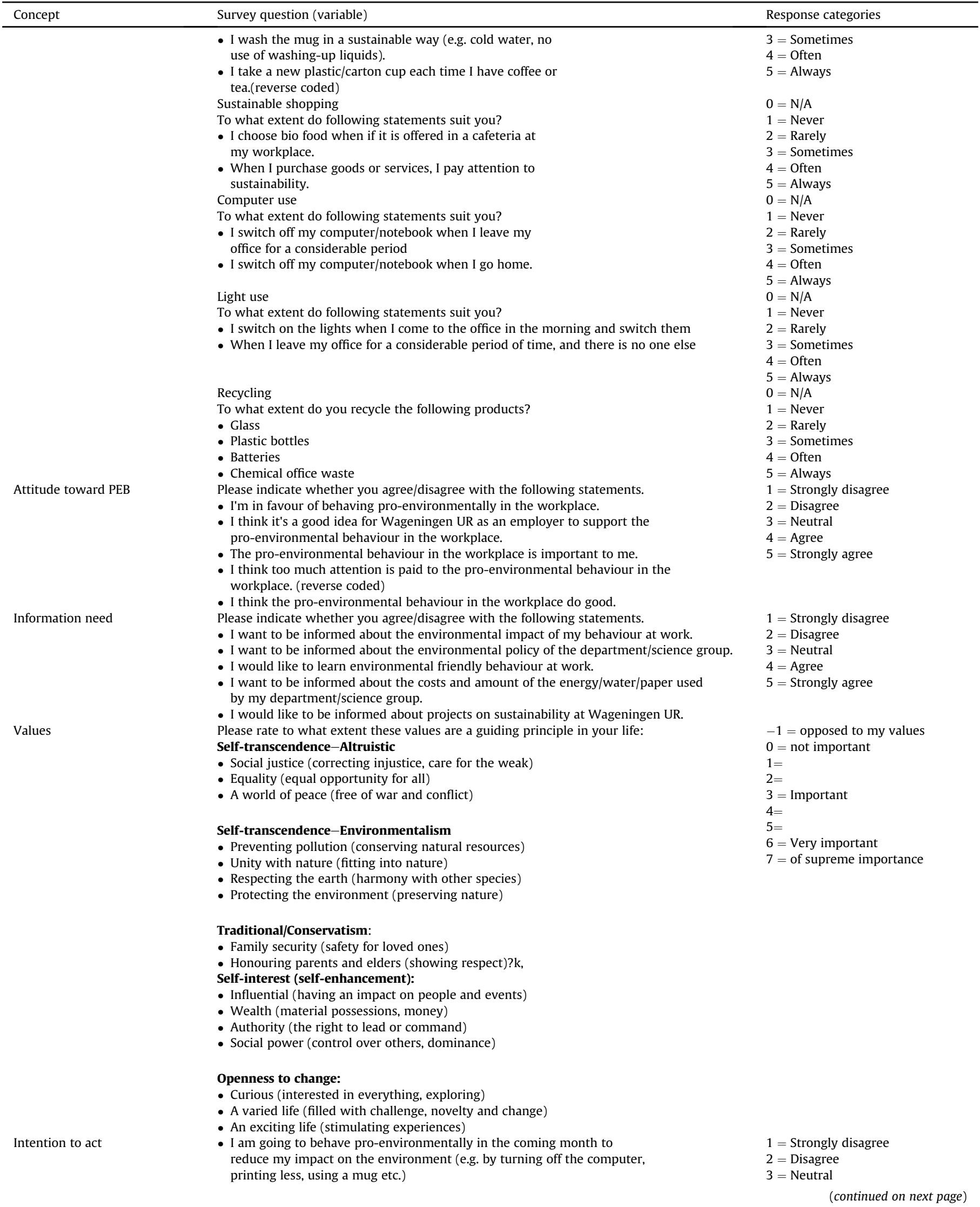


(continued)

Concept

Environmental awareness

Social norms at work

Personal norms

Perceived behavioural control

Situational factors

Leadership boss

Leadership Support

Gender

Age

Education
Survey question (variable)

Please indicate whether you agree/disagree with the following statements.

- Environmental pollution affects my health

- Environmental problems have consequences for my life

- I worry about environmental problems

- I can see with my own eyes that environment is deteriorating

- Environmental problems are a risk for the future of my children

- Environmental problems are exaggerated (reverse coded)

- Too much attention is paid to environmental problems (reverse coded)

- The attention given to the greenhouse effect is exaggerated (reverse coded)

- Saving threatened species in unnecessary luxury (reverse coded)

- A better environment starts with me.

- People who do not take the environment into account try to escape their responsibility

What in your opinion should your colleagues do at work?

- Print double-sided?

- Copy double-sided?

- Recycle paper?

- Turn off the computer/notebook when not in use?

- Arrange a telephone or video-conference instead of travelling to a business meeting?

What do you think you have to do at work?

- Print double-sided?

- Copy double-sided?

- Recycle paper?

- Turn off the computer/notebook when not in use?

- Arrange a telephone or video-conference instead of travelling to a business meeting?

- Whether I perform pro-environmentally is entirely up to me.

- If I wanted to, I could easily behave pro-environmentally in the workplace.

- Wageningen UR as an employer provides good possibilities to show the pro-environmental behaviour.

- The current facilities for recycling are sufficient at my working place.

Please indicate your agreement/disagreement with the following statements about the employer.

- I show the pro-environmental behaviour, when my boss/head of the department behaves pro-environmentally in the workplace.

- It is important to me that my boss/head of the department shows pro-environmental behaviour at work.

- Seeing my boss/head of the department acting pro-environmentally influences my own acting.

- My boss/head of the department supports me in showing pro-environmental behaviour at work.

- My employer informs me about the environmental impact of my behaviour at work

- My employer informs me about projects on sustainability at Wageningen UR

- My employer informs me about environmental policy of my department/science group.

- I learn environmental friendly behaviour at work.

- There is a supervisory support for the environmental effort of the employees.

- Gender

- What is your age?

- What is your highest education level?
- Which kind of employment do you have in your department?
Response categories

$4=$ Agree

$5=$ Strongly agree

$1=$ Strongly disagree

$2=$ Disagree

$3=$ Neutral

$4=$ Agree

$5=$ Strongly agree

$1=$ Absolutely not

$5=$ Absolutely

$1=$ Absolutely not

$5=$ Absolutely

$1=$ Strongly disagree

$2=$ Disagree

$3=$ Neutral

$4=$ Agree

$5=$ Strongly agree

$1=$ Strongly disagree

$2=$ Disagree

3 = Neutral

$4=$ Agree

$5=$ Strongly agree

$1=$ Absolutely not

$2=$

$3=$

$5=$ Absolutely

$1=$ Absolutely not

$2=$

$3=$

$5=$ Absolutely

Male

Female

Less than high school graduate High school graduate or equivalent Specialized/Vocational/Technical training (MBO)

Bachelor degree (HBO)

Master's degree

Doctoral Degree

Supportive personnel Scientific personnel 


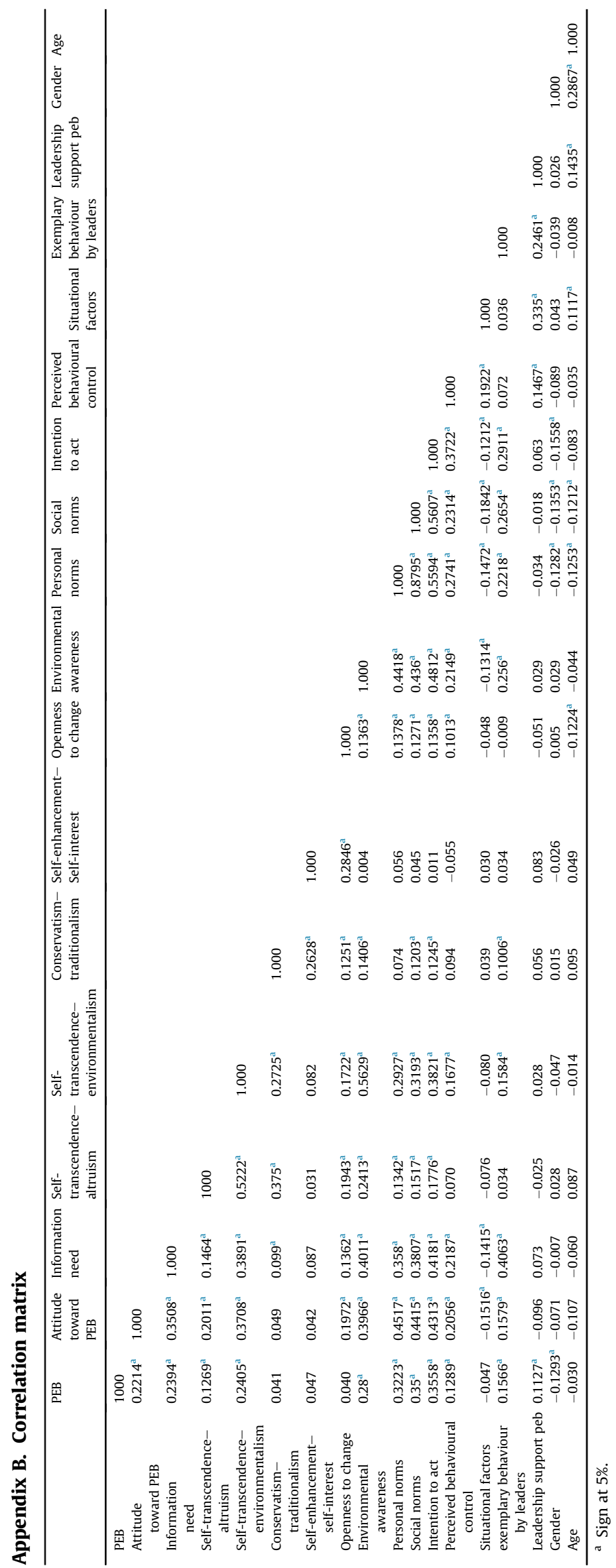




\section{References}

Abrahamse, W., Steg, L., Gifford, R., Vlek, C., 2009. Factors influencing car use for commuting and the intention to reduce it: a question of self-interest or morality? Transp. Res. Part Traffic Psychol. Behav. 12, 317-324.

Ajzen, I., 1991. The theory of planned behavior. Organ. Behav. Hum. Decis. Process. $50,179-211$.

Ajzen, I., Fishbein, M., 2004. Attitudes and the Attitude-behavior Relation: Reasoned and Automatic Processes. John Wiley.

Andersson, L., Shivarajan, S., Blau, G., 2005. Enacting ecological sustainability in the MNC: a test of an adapted value-belief-norm framework. J. Bus. Ethics 59, 295-305.

Bamberg, S., Schmidt, P., 2003. Incentives, morality, or habit? Predicting students' car use for University routes with the models of ajzen, schwartz, and Triandis. Environ. Behav. 35, 264-285.

Bandura, A., 1997. Self-efficacy: the Exercise of Control. W.H. Freeman and Company, New York.

Barr, S., Gilg, A., 2006. Sustainable lifestyles: framing environmental action in and around the home. Geoforum 37, 906-920.

Barr, S., Gilg, A.W., Ford, N.J., 2001. A conceptual framework for understanding and analysing attitudes towards household-waste management. Environ. Plan. 33, 2025-2048.

Bartlett, D., 2003. A comparative study of ethical decision making amongst managers in large private-sector U.K. companies. In: Pava, M.L., Primeaux, P. (Eds.), Spiritual Intelligence at Work: Meaning, Metaphor, and Morals (Research in Ethical Issues in Organizations, vol. 5. Emerald, pp. 213-237.

Becker, L.J., 1978. Joint effect of feedback and goal setting on performance: a field study of residential energy conservation. J. Appl. Psychol. 63 (4), 428-433.

Blok, V., 2013. The power of speech acts: reflections on a performative concept of ethical oaths in economics and business. Rev. Soc. Econ. 71 (2), 187-208.

Boldero, J., 1995. The prediction of household recycling of newspapers: the role of attitudes, intentions, and situational Factors1. J. Appl. Soc. Psychol. 25, 440-462.

Borden, R.J., Schettino, A.P., 1979. Determinants of environmentally responsible behavior. J. Environ. Educ. 10, 35-39.

Borgstede, C.V., Anders, B., 2002. Pro-environmental Behaviour: Situational Barriers and Concern for the Good at Stake. Göteborg Psychological Reports, 32.

Bratt, C., 1999. The impact of norms and assumed consequences on recycling behavior. Environ. Behav, 31, 630-656.

Cassell, C., Johnson, P., Smith, K., 1997. Opening the Black Box: corporate codes of ethics in their organisational context. J. Bus. Ethics 16 (10), 1077-1093.

Clark, C.F., Kotchen, M.J., Moore, M.R., 2003. Internal and external influences on proenvironmental behavior: participation in a green electricity program. J. Environ. Psychol. 23, 237-246.

Conner, M., Armitage, C.J., 1998. Extending the theory of planned behavior: a review and avenues for further research. J. Appl. Soc. Psychol. 28 (5), 1429-1464.

Cordano, M., Marshall, R.S., Silverman, M., 2010. How do small and medium enterprises go 'Green'? A study of environmental management programs in the U.S. wine industry. J. Bus. Ethics 92, 463-478.

Csutora, M., 2012. One more awareness Gap? the behaviour-impact Gap problem. J. Consum. Policy 35 (1), 145-163.

Daily, B.F., Bishop, J.W., Govindarajulu, N., 2008. A Conceptual Model for Organizational Citizenship Behavior Directed Toward the Environment. Business \& Society.

De Groot, J.I.M., Steg, L., 2008. Value orientations to explain beliefs related to environmental significant behavior. Environ. Behav. 40, 330-354.

De Groot, J.I.M., Steg, L., 2009. Mean or green: which values can promote stable proenvironmental behavior? Conserv. Lett. 2, 61-66.

Dentoni, D., Blok, V., Wesselink, R., Lans, T., 2012. Developing human capital for Agri-food firms' multi-stakeholder interactions. Int. Food Agribus. Manag. Rev. 15 (A), 61-68.

Derksen, L., Gartrell, J., 1993. The social context of recycling. Am. Sociol. Rev. 58, 434-442.

Dietz, T., Stern, P.C., Guagnano, G.A., 1998. Social structural and social psychological bases of environmental concern. Environ. Behav. 30, 450-471.

Duerden, M.D., Witt, P.A., 2010. The impact of direct and indirect experiences on the development of environmental knowledge, attitudes, and behavior. J. Environ. Psychol. 30 (4), 379-392.

Egri, C.P., Herman, S., 2000. Leadership in the North American environmental Sector: values, leadership styles, and contexts of environmental leaders and their organizations. Acad. Manage. J. 43, 571-604.

Epstein, M.J., 2008. Making Sustainability Work. Best Practices in Managing and Measuring Corporate Social, Environmental, and Economic Impacts. Greenleaf, San Francisco, CA.

Fliegenschnee, M., Schelakovsky, A., 1998. Umweltpsychologie und Umweltbildung: eine Einführung aus humanökologischer Sicht. Facultas-Univ.-Verl.

Fornara, F., Carrus, G., Passafaro, P., Bonnes, M., 2011. Distinguishing the sources of normative influence on proenvironmental behaviors. Group Process. Intergr: Relat. 14, 623-635.

Friends of the Earth, 2009. Overconsumption. Our Use of the World's Natural Resources. Friends of the Earth, Washington.

Fujii, S., 2006. Environmental concern, attitude toward frugality, and ease of behavior as determinants of pro-environmental behavior intentions. J. Environ. Psychol. 26, 262-268.
Gatersleben, B., Steg, L., Vlek, C., 2002. Measurement and determinants of environmentally significant consumer behavior. Environ. Behav. 34, 335-362.

Grob, A., 1991. Meinung, Verhalten, Umwelt : ein psychologisches UrsachennetzModell umweltgerechten Verhaltens. P. Lang, Bern; New York.

Grob, A., 1995. A structural model of environmental attitudes and behaviour. J. Environ. Psychol. 15, 209-220.

Guagnano, G.A., Stern, P.C., Dietz, T., 1995. Influences on attitude-behavior relationships. Environ. Behav. 27, 699-718.

Hargreaves, T., 2011. Practice-ing behaviour change: applying social practice theory to pro-environmental behaviour change. J. Consum. Cult. 11 (1), 79-99.

Harland, P., Staats, H., Wilke, H.A.M., 1999. Explaining proenvironmental intention and behavior by personal norms and the theory of planned behavior. J. Appl. Soc. Psychol. 29, 2505-2528.

Harland, P., Staats, H., Wilke, H.A.M., 2007. Situational and personality factors as direct or personal norm mediated predictors of pro-environmental behavior: questions derived from norm-activation theory. Basic Appl. Soc. Psychol. 29, 323-334.

Heath, Y., Gifford, R., 2002. Extending the theory of planned behavior: predicting the use of public transportation. J. Appl. Soc. Psychol. 32, 2154-2189.

Hines, J.M., Hungerford, H.R., Tomera, A.N., 1987. Analysis and synthesis of research on responsible environmental behavior: a meta-analysis. J. Environ. Educ. 18, 1-8.

Howell, R.A., 2013. It's not (just) "the environment, stupid!" Values, motivations, and routes to engagement of people adopting lower-carbon lifestyles. Glob. Environ. Change 23 (1), 281-290.

Jackall, R., 1988. Moral Mazes: the World of Corporate Managers. Oxford UP, Oxford. Jacqueline, O.R.T.B., 1999. Deliberative and Inclusionary Processes. CSERGE, School of Environmental Sciences, Norwich.

Juárez-Nájera, M., Rivera-Martínez, Hafkamp, W.A., 2010. An explorative sociopsychological model for determining sustainable behavior: pilot study in German and Mexican Universities. J. Clean. Prod. 18 (7), 686-694.

Kaiser, F.G., Gutscher, H., 2003. The proposition of a general version of the theory of planned behavior: predicting ecological behavior. J. Appl. Soc. Psychol. 33, 586-603.

Kaiser, F.G., Wölfing, S., Fuhrer, U., 1999. Environmental attitude and ecological behaviour. J. Environ. Psychol. 19, 1-19.

Karp, D.G., 1996. Values and their effect on pro-environmental behavior. Environ Behav. 28, 111-133.

Katzev, R.D., Johnson, T.R., 1984. Comparing the effects of monetary incentives and foot-in-the-door strategies in promoting residential electricity conservation. J. Appl. Soc. Psychol. 14, 12-27.

Ki-Hoon, L., Barker, M., Mouasher, A., 2013. Is it even espoused? An exploratory study of commitment to sustainability as evidenced in vision, mission, and graduate attribute statements in Australien universities. J. Clean. Prod. 48 20-28.

Kip Viscusi, W., Huber, J., Bell, J., 2011. Promoting recycling: private values, social norms, and economic incentives. Am. Econ. Rev. 101, 65-70.

Klöckner, C.A., Oppedal, I.O., 2011. General vs. domain specific recycling behaviour applying a multilevel comprehensive action determination model to recycling in Norwegian student homes. Resour. Conserv. Recycl. 55, 463-471.

Kollmuss, A., Agyeman, J., 2002. Mind the gap: why do people act environmentally and what are the barriers to pro-environmental behavior? Environ. Educ. Res. 8 , 239-260.

Kronenberg, J., 2007. Making consumption “reasonable”. J. Clean. Prod. 15 (6) $557-566$.

Kürzinger, E., 2004. Capacity building for profitable environmental management. J. Clean. Prod. 12 (3), 237-248.

Lambrechts, W., Mula, I., Ceulemans, K., Molderez, I., 2013. The integration of competences for sustainable development in higher education: an analysis of bachelor programs in management. J. Clean. Prod. 48, 65-73.

Lans, T., Blok, V., Wesselink, R., 2014. Learning apart and together: towards an integrated competence framework for sustainable entrepreneurship in higher education. J. Clean. Prod. 62 (1), 37-47.

Lehman, P.K., Geller, E.S., 2004. Behavior analysis and environmental protection: accomplishments and potential for more. Behav. Soc. Issues 13, 13-32.

Liebrand, W.B.G., Messick, D.M., Wilke, H.A.M., 1992. Social Dilemmas : Theoretical Issues and Research Findings. Pergamon Press, Oxford; New York.

Liedtka, J., 1991. Organisational value contention and managerial mindsets. J. Bus Ethics 10, 543-557.

Lozano, R., Lukman, R., Lozano, F.J., Huisingh, D. Lambrechts, W., 2013. Declarations for sustainability in higher education becoming better leaders, through addressing the university system. J. Clean. Prod. 48, 10-19.

Lukman, R., Lozano, R., Vamberger, T., Krajnc, M., 2013. Addressing the attitudinal gap towrads improving the environment: a case study from a primary school in Slovenia. J. Clean. Prod. 48, 93-100.

Mannetti, L., Pierro, A., Livi, S., 2004. Recycling: planned and self-expressive behaviour. J. Environ. Psychol. 24, 227-236.

Marchand, A., Walker, S., 2008. Product development and responsible consumption: designing alternatives for sustainable lifestyles. J. Clean. Prod. 16 (11) 1163-1169.

Matthies, E., Selge, S., Klackner, C.A., 2012. The role of parental behaviour for the development of behaviour specific environmental norms 'The example of recycling and re-use behaviour. J. Environ. Psychol. 32, 277-284.

Mckenzie-Mohr, D., 2000. New ways to promote proenvironmental behavior: promoting sustainable behavior: an introduction to community-based social marketing. J. Soc. Issues 56, 543-554. 
Meinhold, J.L., Malkus, A.J., 2005. Adolescent environmental behaviors. Environ. Behav. 37, 511-532.

Nordlund, A.M., Garvill, J., 2002. Value structures behind proenvironmental behavior. Environ. Behav. 34, 740-756.

Nye, M., Hargreaves, T., 2010. Exploring the social dynamics of proenvironmental behavior change. J. Ind. Ecol. 14, 137-149.

Oreg, S., Katz-Gerro, T., 2006. Predicting proenvironmental behavior cross-nationally. Environ. Behav. 38, 462-483.

Pappas, E., Pierrakos, O., Nagel, R., 2013. Using Bloom's taxonomy to teach sustainability in multiple contexts. J. Clean. Prod. 48, 54-64.

Ramayah, T., Lee, J.W.C., Lim, S., 2012. Sustaining the environment through recycling: an empirical study. J. Environ. Manage. 102, 141-147.

Ramus, C.A. Steger, U, 2000. The roles of supervisory support behaviors and environmental policy in employee "Ecoinitiatives" at leading-edge European companies. Acad. Manag. J. 43, 605-626.

Rioux, L., 2011. Promoting pro-environmental behaviour: collection of used batteries by secondary school pupils. Environ. Educ. Res. 17, 353-373.

Robertson, J.L., Barling, J., 2012. Greening organizations through leaders' influence on employees' pro-environmental behaviors. J. Organ. Behav. 34 (2), 176-194.

Rodruguez-Barreiro, L.M., Fernandez-Manzanal, R., Serra, L.M., Carrasquer, J. Murillo, M.B., Morales, M.J., Calvo, J.M., Del Valle, J., 2013. Approach to a causa model between attitudes and environmental behaviour. A graduate case study. J. Clean. Prod, 48, 116-125.

Rosner, W.J., 1995. Mental models for sustainability. J. Clean. Prod. 3 (1-2) 107-121.

Schultz, P.W., Oskamp, S., Mainieri, T., 1995. Who recycles and when? A review of personal and situational factors. J. Environ. Psychol. 15, 105-121.

Schultz, P.W., Zelezny, L.C., 1998. Values and proenvironmental behavior a fivecountry survey. J. Cross. Cult. Psychol. 29, 540-558.

Schwartz, S.H., 1994. Are there universal aspects in the structure and contents of human values? J. Soc. Issues 50, 19-45.

Schwartz, S.H., Leonard, B., 1977. Normative influences on altruism. In: Advances in Experimental Social Psychology. Academic Press.

Schwartz, S.H. Mark, PZ, 1992. Universals in the content and structure of values: theoretical advances and empirical tests in 20 countries. In: Advances in Experimental Social Psychology. Academic Press.

Sedlacek, S., 2013. The role of universities in fostering sustainable development at the regional level. J. Clean. Prod. 48, 74-84.

Steg, L., 1999. Verspilde Energie?. SCP Report No. 126 Social and Cultural Planning Office of the Netherlands, The Hague, the Netherlands.
Steg, L., Vlek, C., 2009. Encouraging pro-environmental behaviour: an integrative review and research agenda. J. Environ. Psychol. 29, 309-317.

Stern, P.C., 1999. Information, incentives, and proenvironmental consumer behavior. J. Consum. Policy 22, 461-478.

Stern, P.C., Dietz, T., 1994. The value basis of environmental concern. J. Soc. Issues 50, 65-84.

Stern, P.C., Dietz, T., Abel, T., Guagnano, G.A., Kalof, L., 1999. A value-belief-norm theory of support for social movements: the case of environmentalism. Hum. Ecol. Rev. 6, 81-97.

Subhabrata Bobby, B., Iyer, E.S., Kashyap, R.K., 2003. Corporate environmentalism: antecedents and influence of industry type. J. Mark. 67, 106-122.

Swami, V., Chamorro-Premuzic, T., Snelgar, R., Furnham, A., 2011. Personality, individual differences, and demographic antecedents of self-reported household waste management behaviours. J. Environ. Psychol. 31, 21-26.

Thøgersen, J., 1999. The ethical consumer. Moral norms and packaging choice. J. Consum. Policy 22, 439-460.

Van Birgelen, M., Semeijn, J., Keicher, M., 2009. Packaging and proenvironmental consumption behavior. Environ. Behav. 41, 125-146.

Veldhuizen, M., Blok, V., Dentoni, D., 2013. Organisational drivers of capabilities for multi-stakeholder dialogue and knowledge integration. J. Chain Netw. Sci. 13 (2), 107-117.

Wageningen UR, 2012a. Show It! Interpretation Sustainability Wageningen UR 2013+2014. Wageningen UR, Wageningen.

Wageningen UR, 2012b. Annual Report 2012. Wageningen UR, Wageningen.

Wall, R., Devine-Wright, P., Mill, G.A., 2007. Comparing and combining theories to explain proenvironmental intentions. Environ. Behav. 39, 731-753.

Whitmarsh, L., O'neill, S., 2010. Green identity, green living? the role of proenvironmental self-identity in determining consistency across diverse proenvironmental behaviours. J. Environ. Psychol. 30 (3), 305-314.

Wirtenberg, J., Russell, W.G., Lipsky, D., 2008. The Sustainable Enterprise Fieldbook: When it All Comes Together. Amacom, New York.

WWF, 2012. Living Planet Report. WFF, Gland.

Yen, Y.-X., Yen, S.-Y., 2012. Top-management's role in adopting green purchasing standards in high-tech industrial firms. J. Bus. Res, 65, 951-959.

Zsóka, Á., Szerényi, Z.M., Széchy, A., Kocsis, T., 2013. Greening due to environmental education? Environmental knowledge, attitudes, consumer behavior and everyday pro-environmental activities of Hungarian high school and university students. J. Clean. Prod. 48, 128-138. 